\title{
Allele variations in the OCA2 gene (pink-eyed-dilution locus) are associated with genetic susceptibility to melanoma
}

\author{
Anne-Sophie Jannot ${ }^{1}$, Roubila Meziani ${ }^{2}$, Guylene Bertrand ${ }^{3}$, Benedicte Gérard ${ }^{2}$, \\ Vincent Descamps ${ }^{4}$, Alain Archimbaud ${ }^{4}$, Catherine Picard ${ }^{4}$, Laurence Ollivaud ${ }^{5}$, \\ Nicole Basset-Seguin ${ }^{5}$, Delphine Kerob ${ }^{5}$, Guy Lanternier ${ }^{6}$, Celeste Lebbe ${ }^{5}$, P Saiag ${ }^{7}$, \\ Beatrice Crickx ${ }^{4}$, Françoise Clerget-Darpoux ${ }^{1}$, Bernard Grandchamp ${ }^{2}$, Nadem Soufir ${ }^{* 2}$, \\ and Melan-Cohort ${ }^{8}$
}

\begin{abstract}
${ }^{1}$ Unité INSERM 535 'Génétique Epidémiologique et Structure des Populations Humaines', Hôpital Paul Brousse, Villejuif, France; ${ }^{2}$ Laboratoire de Biochimie Hormonale et Génétique, Hôpital Bichat-Claude Bernard, AP-HP, Faculté de Médecine Paris VII, France; ${ }^{3}$ Département d'épidémiologie, de biostatistiques et de recherche clinique, Hôpital Bichat-Claude Bernard, Paris, France; ${ }^{4}$ Service de Dermatologie, Hôpital Bichat-Claude Bernard, Paris, AP-HP, Faculté de Médecine Paris VII, France; ${ }^{5}$ Service de Dermatologie, Hôpital Saint-Louis, AP-HP, Faculté de Médecine Paris VII, Paris, France; ${ }^{6}$ Service de Dermatologie, Hopital Percy, Clamart, France; ${ }^{7}$ Service de Dermatologie, Hopital Ambroise Paré, AP-HP, Faculté de Médecine Paris-Ile de France Ouest, Boulogne Billancourt, France
\end{abstract}

The occuloalbinism 2 (OCA2) gene, localized at 15q11, encodes a melanosomal transmembrane protein that is involved in the most common form of human occulo-cutaneous albinism, a human genetic disorder characterized by fair pigmentation and susceptibility to skin cancer. We wondered whether allele variations at this locus could influence susceptibility to malignant melanoma (MM). In all, 10 intragenic single-nucleotide polymorphisms (SNPs) were genotyped in 113 patients with melanomas and in 105 Caucasian control subjects with no personal or family history of skin cancer. By comparing allelic distribution between cases and controls, we show that MM and OCA2 are associated ( $p$ value $=0.030$ after correction for multiple testing). Then, a recently developed strategy, the 'combination test' enabled us to show that a combination formed by two SNPs was most strongly associated to MM, suggesting a possible interaction between intragenic SNPs. In addition, the role of OCA2 on MM risk was also detected using a logistic model taking into account the presence of variants of the melanocortin 1 receptor gene (MC1R, a key pigmentation gene) and all pigmentation characteristics as melanoma risk factors. Our data demonstrate that a second pigmentation gene, in addition to $M C 1 R$, is involved in genetic susceptibility to melanoma.

European Journal of Human Genetics (2005) 13, 913-920. doi:10.1038/sj.ejhg.5201415;

published online 27 April 2005

Keywords: melanoma; combination test; association study; SNP interaction

\footnotetext{
*Correspondence: Dr Soufir, Biochimie Hormonale et Génétique, Hôpital Bichat-Claude Bernard, 46 rue Henri Huchard, 75018 Paris, France.

Tel: + 331402585 53; Fax: + 331402587 85;

E-mail: nsoufir@yahoo.com

${ }^{8}$ Melan-Cohort is a prospective cohort of melanoma patients constituted by all the university-affiliated departments of Dermatology of the Paris area Received 6 October 2004; revised 23 February 2005; accepted 24 February 2005; published online 27 April 2005
}

Introduction

Malignant melanoma (MM) is increasing in most Caucasian populations, with an incidence doubling every 10 years. ${ }^{1}$ Approximately $10 \%$ of $\mathrm{MM}$ cases are familial, and germline mutations affecting two highly penetrant melanoma-predisposing genes, $C D K N 2 A$ and $C d k 4$, have been identified. $^{2-5}$ 
In addition, loss-of-function variants of the human melanocortin-1 receptor gene, MC1R, which plays a crucial role in pigmentation, have been shown to be important risk factors determining sporadic melanoma. ${ }^{6-8}$

Tyrosinase-positive oculocutaneous albinism (OCA, type II), the most prevalent type of albinism, ${ }^{9}$ is an inherited autosomal recessive disorder due to germline mutations of the $P$ gene (occuloalbinism 2 (OCA2)). OCA2 maps to chromosome 15q11.2-12, consists of 25 exons, encoding a vacuolar 838 -amino-acid protein ${ }^{10,11}$ that is the human homologue of the mouse pink-eyed dilution locus, $p .^{12,13}$ The product of the mammalian $p$ gene is an integral membrane protein with a predicted 12-transmembrane domain structure, resembling a channel or transporter, ${ }^{12-15}$ and recessive mutations at the mouse $p$ locus result in diminished coat and ocular pigmentation. The $p$ locus plays an important role in melanosome biogenesis, and controls the eumelanin content in melanocytes ${ }^{16-20}$ in part via the processing and trafficking of tyrosinase - the rate-limiting enzyme in melanin synthesis. ${ }^{21,22}$

Albino patients are highly predisposed to sun-induced skin cancers including mainly non-melanoma skin cancers (NMSC), but also less frequently melanoma. The OCA2 gene is highly polymorphic, ${ }^{23}$ and is suspected of playing an important role in human pigmentation. ${ }^{24,25}$ Accordingly, it has recently been shown that two OCA2 nonsynonymous variants are partly responsible for determining normal phenotypic variations in human eye colour, suggesting that variations of this gene may constitute an inherited biomarker of the skin cancer risk. ${ }^{26}$

Therefore, in this study, we investigated the effect of germline allele variations at the OCA2 gene on susceptibility to MM. In addition, we also studied whether the effect of OCA2 on $\mathrm{MM}$ persists after stratification for pigmentation characteristics.

\section{Materials and methods Study population}

A total of 120 patients with MM and 125 controls were recruited. In all, 29\% of the MM patients were incident cases, and $71 \%$ were prevalent cases. The median time between the diagnosis of melanoma and blood sampling was 44.6 months. All participants were French Caucasians and had been recruited by the Dermatology Departments of four hospitals in Paris (France): the Bichat ClaudeBernard, Percy, Ambroise Paré and Saint-Louis Hospitals. The study population consisted of patients between 20 and 80 years of age with histologically proved MM. Seven patients displaying $C D K N 2 A$ germline mutations were excluded.

A previously described French Caucasian control group, ${ }^{14}$ with no personal or family history of skin cancer, was used for comparison of OCA2 allele frequencies. The control subjects, between 20 and 80 years of age, were recruited from the same hospitals as the MM cases to provide a typical sample of people living in the same demographic area.

The Medical Ethics Committee (CCPPRB) approved the study protocol. Informed consent was obtained from all the patients and control subjects enrolled in the study.

\section{Collecting data about risk factors for MM}

The participants underwent a standardized personal interview conducted by a dermatologist, and a total skin examination was performed to collect data, which was reported using a pre-printed examination report form.

Information was recorded about skin colour (classified as dark, medium, or fair), eye colour (classified as dark (brown or black) or light (blue, green/hazel, or grey)) and original (before greying) hair colour (classified using five categories: red, blond, light- or dark-brown, and black). The nevus body count $(<$ or $\geqslant 50$ nevi), the presence or absence of atypical mole syndrome (50 or more nevi, with at least 3 of them being clinically atypical, that is, $6 \mathrm{~mm}$ or more in size, and characterized by variable pigmentation, indistinct borders and irregular outline), ${ }^{27}$ and the presence or absence of solar lentigines were also assessed by means of physical examination by a dermatologist. Skin types were assessed according to the Fitzpatrick classification as follows: always burns never tans (skin type I); always burns then tans (skin type II); always tans sometimes burns (skin type III); and always tans never burns (skin type IV). The control subjects underwent the same interview and examination.

Genomic DNA was isolated from peripheral blood leukocytes of all the participants by routine methods. ${ }^{28}$

\section{OCA2 single-nucleotide polymorphism (SNP) genotyping}

A total of 10 SNPs on the OCA2 gene were studied (Table 1). Eight SNPs were chosen from the NCBI SNP database (http://www.ncbi.nlm.nih.gov/SNP/index.html) or The International Albinism Database (http://www.cbc.umn.edu/ tad/), and two (IVS13 + 112 A/G and IVS13 + $180 \mathrm{C} / \mathrm{T}$ ) were identified by sequencing. Five SNPs (two exonic and three intronic) were genotyped by sequencing the whole of exon 13 of OCA2 (Table 1). The other five SNPs were genotyped using the Snap Shot procedure, according to the manufacturer's instructions (Perkin-Elmer), by using a specific primer extension reaction (Tables 1 and 2). All profiles corresponding to the different genotypes were confirmed by direct sequencing of the PCR products.

\section{Detection of MC1R functional variants}

The MC1R coding sequence was amplified by PCR with two overlapping couples of primers, as described previously. ${ }^{29}$ Sequence analysis was performed on an ABI-Prism 3100 automated DNA sequencer using $10 \mathrm{ng}$ of PCR purified products and Big-Dye Terminator Cycle Sequencing 
kits (Perkin-Elmer), according to the manufacturer's instructions. For genetic analysis, only the $M C 1 R$ polymorphisms retained were those (a) previously shown to be loss-of-function variants by functional studies ${ }^{30-35}$ and/or (b) associated with MM risk. 6,7,35

\section{Statistical analyses}

Association between MM and pigmentation characteristics The association between $\mathrm{MM}$ and each pigmentation characteristic was tested using a $\chi^{2}$ test.

\section{Genotype data}

SNPs for which the minor allele was rare (fewer than five individuals heterozygous or homozygous for the minor allele) were not included. The degree of linkage disequilibrium (LD) between the different SNPs was calculated using the correlation coefficient as described previously. ${ }^{36}$

Table 1 Characterization of the OCA2 SNPs: gene location, allele variation, genotyping method

\begin{tabular}{|c|c|c|c|c|}
\hline SNP name & $\begin{array}{l}\text { Gene } \\
\text { location }\end{array}$ & $\begin{array}{l}\text { SNP } \\
\text { nomenclature }\end{array}$ & Alleles $^{\mathrm{a}}$ & $\begin{array}{l}\text { Genotyping } \\
\text { method }\end{array}$ \\
\hline R305W & Exon 9 & rs1800401 & $\mathrm{C} / \mathrm{T}$ & SnapShot \\
\hline R419Q & Exon 13 & rs1800407 & $\mathrm{G} / \mathrm{A}$ & Sequencing \\
\hline L440F & Exon 13 & rs1800408 & $\mathrm{G} / \mathrm{C}$ & Sequencing \\
\hline IVS13+25 & Intron 13 & - & $\mathrm{A} / \mathrm{G}$ & Sequencing \\
\hline IVS13+112 & Intron 13 & - & $\mathrm{A} / \mathrm{G}$ & Sequencing \\
\hline IVS13+180 & Intron 13 & - & $\mathrm{C} / \mathrm{T}$ & Sequencing \\
\hline IVS13-15 & Intron 13 & - & $\mathrm{T} / \mathrm{C}$ & SnapShot \\
\hline I722T & Exon 22 & rs1800417 & $\mathrm{T} / \mathrm{C}$ & SnapShot \\
\hline A776A & Exon 23 & rs1800419 & $\mathrm{T} / \mathrm{C}$ & SnapShot \\
\hline G780G & Exon 24 & rs1800420 & $\mathrm{C} / \mathrm{T}$ & SnapShot \\
\hline
\end{tabular}

${ }^{a}$ major allele/minor allele.
Test of the association between OCA2 and MM Allelic distribution between cases and controls was first compared for each individual SNP and a permutation procedure was used to correct for multiple testing. The same analysis was then performed for genotypic distribution.

The association was further examined with a recently developed method, the 'combination test', 37 that consists in comparing the distribution of the genotypes resulting from all possible combinations formed by a variable number of SNPs in the MM cases and controls. With seven studied SNPs, seven tests are performed for single SNPs, 21 (7!/5!2!) for combinations of two SNPs, 35 for combinations of three SNPs and so on, giving a total of 127 performed tests for all possible combinations of these SNPs. All these tests are in fact interdependent, because many of the tests are nested in others, and because the SNPs are in LD. To allow for this dependency when correcting for multiple testing, a permutation procedure was used to calculate the level of significance of the test. Furthermore, asymptotic conditions did not apply for each individual test. This permutation procedure was therefore also useful to estimate the level of significance of each test, as it provides an empirical distribution for each test. A simulation study ${ }^{37}$ has shown for a quantitative trait locus that the 'combination test' has in complex situations of gene involvement a better power than the two commonly used tests, the association test of each single SNP and the association test of the genotypes formed by all SNPs.

Using the 'combination test' enabled us to extract all the combinations that were significantly associated with MM at 5\%-Type 1 error. These combinations are helpful for determining disease-risk and protective genotypes. As many nested combinations could be associated with $\mathrm{MM}$, we implemented a strategy to extract from these

Table 2 PCR and extension DNA oligonucleotides used for OCA2 SNPs genotyping

\begin{tabular}{|c|c|c|}
\hline Primer name & & DNA size product $(p b)$ \\
\hline \multicolumn{3}{|l|}{$P C R$ primers } \\
\hline OCA2EX13F & 5' ATG GGG TAA TGT TAG TTT GGC TC 3' & 500 \\
\hline OCA2-EX13R & $5^{\prime}$ CAC AAT CTC CAG GAA AGC AAG GC $3^{\prime}$ & \\
\hline OCA2-EX9F & $5^{\prime}$ AGT AAG GTC GTT GTT TCG TTC TG $3^{\prime}$ & 132 \\
\hline OCA2-EX9R & $5^{\prime}$ GGT CAC CTG GGT TTC TAC ACT TC $3^{\prime}$ & \\
\hline OCA2-EX14F & $5^{\prime}$ GGG CCT TTC ACG ATG TGT ATA GT $3^{\prime}$ & 354 \\
\hline OCA2-EX14R & 5' CAG TCA CCT AAC ATC CCA GTC TT 3' & \\
\hline OCA2-EX22F & 5' CTA TTG TCC TCC TTC CAG ATG GT 3' & 175 \\
\hline OCA2EX22R & $5^{\prime}$ AGG CTA TGT CCA GGC TAA AGT TG $3^{\prime}$ & \\
\hline OCA2-EX23F & $5^{\prime}$ ATG TCC TCT TCC TCC ACA GAT TC $3^{\prime}$ & 225 \\
\hline OCA2-EX23R & 5' CAT CCA GAC TCT ССТ TCA TTT GC $3^{\prime}$ & \\
\hline \multicolumn{3}{|l|}{ Elongation primers } \\
\hline OCA2-R305W & $5^{\prime}$ TT GAG AGA CGG TGT CCA TCA GCA TC $3^{\prime}$ & $25+1$ \\
\hline OCA2-IVS13-15 & $5^{\prime} T$ CAC CTC ACA CAA CCT GTC ACA AAT GGA $3^{\prime}$ & $29+1$ \\
\hline OCA2-1722T & $5^{\prime}$ ACC ACC AGG ACA ATG GCG GCT $3^{\prime}$ & $21+1$ \\
\hline OCA2-A776A & $5^{\prime}(\mathrm{TTT})_{5}$ GTA TGC CCT GGC CTT CGG TGC $3^{\prime}$ & $33+1$ \\
\hline OCA2-G780G & $5^{\prime}(\mathrm{TTT})_{6}$ TCC ATG CAG TCA GCA GCC CCT T $3^{\prime}$ & $37+1$ \\
\hline
\end{tabular}


combinations the most parsimonious one by performing $\chi^{2}$ tests. When considering two nested combinations differing by only one SNP, we concluded that this SNP did not significantly increase the evidence of association if the difference of the $\chi^{2}$ statistics between the two nested combinations was not significant at 5\%, the number of degrees of freedom of the test being the difference in the number of categories between the two combinations.

Effect of OCA2 on pigmentation characteristics The effect of OCA2 on each pigmentation characteristic was also tested using the same statistical methods as for MM. Pigmentation characteristics were considered as binary variables, and included hair colour (red, blond, or light brown versus dark brown or black), skin colour (fair or medium versus dark), eye colour (light versus dark), nevi count ( $<50$ versus $\geqslant 50$ nevi), dorsal lentigines (presence versus absence), and atypical nevus syndrome (presence versus absence).

Stratification for pigmentation characteristics To find out whether the OCA2 MM-related risk was dependent on pigmentation characteristics, stratification was performed for each pigmentation characteristic associated with OCA2 genotype. For each $\mathrm{MM}$-associated pigmentation characteristic group, the association with OCA2 was tested using the 'combination test'.

Multiple logistic regression for OCA2, pigmentation characteristics, and MC1R variants A logistic regression for $\mathrm{MM}$ risk was performed using the following dependent variables: OCA2 genotype formed by the SNP in the most parsimonious combination (combination 3-7), pigmentation characteristics (eye, hair and skin colours, nevi count, and skin type) and $M C 1 R$ variants. To test the involvement of $M C 1 R$, we have taken as dependant variable the presence or absence of $M C 1 R$ functional variants (as defined in Matichard et $a l^{29}$ ). For each variable, it was tested whether dropping it significantly reduced the model fit.

\section{Results \\ Composition of the study population and pigmentation characteristics}

The final group analysed comprised 218 subjects: 113 patients with MM and 105 control subjects. The strongest clinical risk factors identified for $\mathrm{MM}$ were a mole count greater than $50(P<0.0001)$, the presence of an atypical mole syndrome $(P=0.0002)$, fair skin $(P=0.0001)$, and dorsal lentigines $(P<0.0001)$. Less powerful predictors for $\mathrm{MM}$ were fair hair and eye colours (respective $P$-values of 0.003 and 0.002).

\section{Genetic analysis}

A total of 10 SNPs were genotyped (see Materials and methods and Table 1). Three SNPs were excluded from the statistical analysis, because one of the two alleles was absent (G720G, L440F), or rare (I722T, which was present in one patient and two control subjects). The analysis was therefore performed using seven SNPs (Table 3). In addition, a previously reported OCA type 2 pathogenic mutation, V443I, located in exon $13^{9}$ was found in two of the patients but in none of the controls.

The LD study (Table 4) showed that SNP 2 was in strong positive LD with SNP 3, SNP 5 and in strong negative LD with SNP 6, and that SNP 3 was in almost complete LD with SNP 6 and in strong LD with SNP 7. It should be noted that the correlation between the alleles of SNP 3 and SNP 6 in the case sample is weaker $(r=0.89)$ than in the control sample. Then, the information provided by these two SNPs is not redundant and both SNPs have therefore been kept for the analysis.

Association between OCA2 genotype and MM risk Allelic distributions between MM patients and control subjects were significantly different for three different SNPs, SNP 2, 3 and 5 (respective nominal $P$-values: 0.006, 0.009 and 0.009 , see Table 3 ). These associations were still significant after correction for multiple testing.

In contrast, when genotypic distributions were compared for each individual SNP, none of the association tests achieved significance. This could be explained by a loss of power, as three genotypic categories are considered for each SNP instead of two allelic categories.

However, using the 'combination test', which also compares genotypic distribution between patients and controls, we concluded the association between OCA2 and $\mathrm{MM}(P=0.03$ after correction for multiple testing). Indeed, several combinations of SNPs were significantly associated with MM, but none with a single SNP. Among the associated subsets of SNPs, the one retained by the 'combination test' was formed by SNP 3 and 7 (nominal $P$-value: 0.001). When exploring risks associated with the genotypes formed by the alleles of these two SNPs, we found different risks for several genotypes. Notably, there was a major protective genotype, double homozygous for the minor allele of SNP 3 and the major allele of SNP 7, that was present in $11 \%$ of control subjects, but not in any MM patients (Table 5).

\section{Effect of OCA2 on pigmentation characteristics}

After correction for multiple testing, we found that the only pigmentary characteristic associated with OCA2 was eye colour (association of the minor allele of SNP 5 with dark eye colour, $P=0.007)$. This result was confirmed using the combination test, the subset of SNPs that was retained including only the SNP 5. 
Table 3 OCA2 SNPs in patients and control subjects. (a) For each SNP have been calculated the allelic frequency of the major allele and the $P$-value for the allelic distribution between patients and controls. (b) SNP genotypes counts and $P$-value for Hardy-Weinberg equilibrium (HWE) in patients and controls samples

(a)

\begin{tabular}{|c|c|c|c|c|c|}
\hline SNP Number & SNP name & $\begin{array}{c}\text { Minor SNP allele } \\
\text { frequency in MM } \\
\text { patients }\end{array}$ & $\begin{array}{c}\text { Minor SNP allele } \\
\text { frequency in controls }\end{array}$ & Nominal P-value & \\
\hline $\begin{array}{l}1 \\
2 \\
3 \\
4 \\
5 \\
6 \\
7\end{array}$ & $\begin{array}{l}\text { R419Q } \\
\text { IVS13+25 } \\
\text { IVS13+112 } \\
\text { IVS13+180 } \\
\text { R305W } \\
\text { IVS13-15 } \\
\text { A776A }\end{array}$ & $\begin{array}{l}0.08 \\
0.1 \\
0.3 \\
0.04 \\
0.04 \\
0.32 \\
0.48\end{array}$ & $\begin{array}{l}0.09 \\
0.2 \\
0.42 \\
0.05 \\
0.1 \\
0.42 \\
0.47\end{array}$ & $\begin{array}{l}0.35 \\
0.006 \\
0.009 \\
0.935 \\
0.009 \\
0.088 \\
0.287\end{array}$ & \\
\hline \multicolumn{6}{|l|}{ (b) } \\
\hline SNP & Genotype & $\begin{array}{l}\text { Cases number } \\
\quad(n=113)\end{array}$ & $\begin{array}{l}\text { Controls number } \\
\quad(n=105)\end{array}$ & $\begin{array}{l}\text { P-value for HWE in } \\
\text { cases sample }\end{array}$ & $\begin{array}{l}\text { P-value for HWE in } \\
\text { control sample }\end{array}$ \\
\hline 1 & $\begin{array}{l}\text { GG } \\
\text { GA } \\
\text { AA }\end{array}$ & $\begin{array}{c}94 \\
19 \\
0\end{array}$ & $\begin{array}{r}90 \\
12 \\
3\end{array}$ & 0.72 & 0.47 \\
\hline 3 & $\begin{array}{l}\text { AA } \\
\text { AG } \\
\text { GG }\end{array}$ & $\begin{array}{l}57 \\
45 \\
11\end{array}$ & $\begin{array}{l}38 \\
45 \\
22\end{array}$ & 0.93 & 0.70 \\
\hline 4 & $\begin{array}{l}\text { CC } \\
\text { CT } \\
\text { TT }\end{array}$ & $\begin{array}{c}104 \\
8 \\
1\end{array}$ & $\begin{array}{r}95 \\
10 \\
0\end{array}$ & 0.90 & 0.95 \\
\hline 5 & $\begin{array}{l}\text { CC } \\
\text { CT } \\
\text { TT }\end{array}$ & $\begin{array}{c}104 \\
9 \\
0\end{array}$ & $\begin{array}{r}85 \\
18 \\
2\end{array}$ & 0.90 & 0.95 \\
\hline 6 & $\begin{array}{l}\text { CC } \\
\text { CT } \\
\text { TT }\end{array}$ & $\begin{array}{l}16 \\
44 \\
53\end{array}$ & $\begin{array}{l}22 \\
44 \\
39\end{array}$ & 0.65 & 0.62 \\
\hline 7 & $\begin{array}{l}\text { CC } \\
\text { CT } \\
\text { TT }\end{array}$ & $\begin{array}{l}20 \\
69 \\
24\end{array}$ & $\begin{array}{l}29 \\
53 \\
23\end{array}$ & 0.25 & 0.99 \\
\hline
\end{tabular}

Table 4 Degree of LD between the various OCA2 SNPS

\begin{tabular}{lcccccc}
\hline SNP identification & 2 & 3 & 4 & 5 & 6 & 7 \\
\hline 1 & -0.23 & 0.3 & -0.03 & -0.16 & -0.31 & 0.33 \\
2 & & 0.5 & -0.17 & 0.58 & -0.51 & 0.26 \\
3 & & & -0.29 & 0.3 & 0.99 & 0.46 \\
4 & & & & -0.029 & 0.28 & -0.14 \\
5 & & & & & -0.3 & 0.085 \\
6 & & & & & & -0.43 \\
\hline
\end{tabular}

Values of the correlation coefficient were calculated as described in the Materials and methods section.

Persistence of MM risk after stratification for pigmentation characteristics

By applying the 'combination test' to the dark eyes and the light eyes groups, we found that the association of OCA2 with MM persisted after stratification for eye colour ( $P=0.05$ for dark eyes and $P=0.01$ for light eyes). This
Table 5 Number of MM cases and controls for each genotype formed by SNP 3 and 7 (1: major allele, 2: minor allele)

\begin{tabular}{lrrr}
\hline SNP 3 & SNP $~$ & Cases & Controls \\
\hline 11 & 11 & 12 & 9 \\
11 & 12 & 28 & 23 \\
11 & 22 & 17 & 6 \\
12 & 11 & 8 & 8 \\
12 & 12 & 33 & 24 \\
12 & 22 & 4 & 13 \\
22 & 11 & 0 & 12 \\
22 & 12 & 8 & 6 \\
22 & 22 & 3 & \\
TOTAL & 113 & 105 & \\
\hline
\end{tabular}

suggests that although eye color is associated with the OCA2 genotype, it does not account for the MM susceptibility due to OCA2. 
Table 6 Logistic regression using OCA2 genotype (genotypes 12-22 and 22-11 versus all other genotypes) and other MM risk factors (pigmentation characteristics and $M C 1 R$ variants) as dependent variables

\begin{tabular}{lccc}
\hline MM risk factors & P-value & $\begin{array}{c}\text { Regression } \\
\text { coefficient } \\
\text { estimate }\end{array}$ & $\begin{array}{l}\text { Confidence } \\
\text { interval }\end{array}$ \\
\hline Nevi count & $1.10^{-5}$ & 2.64 & {$[1.91,3.36]$} \\
OCA2 genotype & $10^{-4}$ & -2.81 & {$[-3.87,-1.75]$} \\
MC1R variant & $2.10^{-4}$ & 1.42 & {$[1.02,1.82]$} \\
Skin colour & 0.022 & -0.28 & {$[-0.68,0.13]$} \\
Dorsal lentigines & 0.034 & 0.81 & {$[0.43,1.19]$} \\
Eye colour & 0.091 & 0.75 & {$[0.3,1.2]$} \\
Atypical naevi & 0.369 & -0.86 & {$[-1.81,0.1]$} \\
Skin type & 0.488 & 1.33 & {$[0.72,1.95]$} \\
Hair colour & 0.736 & 0.15 & {$[-0.3,0.61]$} \\
\hline
\end{tabular}

The $P$-value corresponds to the removal of one risk factor.

\section{Multiple regression of the OCA2 genotype, MC1R variant and pigmentation characteristics}

$M C 1 R$ functional variants, that are considered to be an important melanoma risk factor, were present in $65 \%$ of the patients and $30 \%$ of the control subjects $(P<0.0001)$.

Interestingly, in a multiple logistic regression analysis on $\mathrm{MM}$ considering the presence or the absence of $M C 1 R$ variants, OCA2 genotypes 12-22 and 22-11 versus all other genotypes and all pigmentation characteristics as dependent variables, removing OCA2 always significantly decreased the model fit. In fact, the OCA2 genotype appeared as the $\mathrm{MM}$ risk factor producing the second greatest decrease in the model fit, after a high nevus count (Table 6). This confirms that even when clinical MM risk factors have been taken into account, OCA2 still has a residual effect on MM risk.

\section{Discussion}

Previous studies have shown that OCA2, a gene involved in the most frequent form of albinism, is highly polymorphic in Caucasian and African populations of different geographic origins. $^{23,38,39}$

In this study, using both conventional statistical methods and the 'combination test', a recently developed test that takes genetic information from numerous genetic markers into account, we have shown the influence of OCA2 genotype on melanoma susceptibility independently of its role on eye colour in a French population.

The combination of SNPs most strongly associated to MM was formed by two SNPs, SNP 3 and 7. Two nonmutually exclusive hypotheses may explain why a combination of two SNPs was more associated to MM than individual SNPs. Firstly, one or several functional variants may be in LD with haplotypes determined by different combinations of SNP 3 and 7. Secondly, several variants may interact to produce a detectable effect on MM risk. It has already been noticed that the individual effect of a variant can be too weak to be detected individually and that interactions of multiple SNPs within the same gene can affect a phenotype. ${ }^{40}$ Therefore, some OCA2 variants and/or their epistatic interaction could possibly produce hypomorphic alleles diminishing eumelanin synthesis.

It should also be noted that a pathogenic mutation of OCA2 previously characterized in OCA type- 2 patients, V443I, was identified in two patients, but in none of the control subjects. As noted previously, ${ }^{41}$ a large number of OCA2 polymorphisms have been reported and examination of a wider range of common alleles together with a comprehensive search for variation within the OCA2 gene is needed to fully understand the genetic relationship between MM and the OCA2 locus.

An association between OCA2 and pigmentation characteristics has recently been suggested. ${ }^{24,26,41,42}$ The association of SNP 5 with eye colour has been previously shown in populations of different geographic origins. ${ }^{41,43}$ The replication of this result in a French population enhanced the role of OCA2 in eye colour. However, contrary to these studies, we observed no association of SNP 1 with eye colour, a result that may be either due to the different geographic origin of our population or due to the different classification used for eye colour in our study.

In addition, our results show that OCA2-related MM risk persisted after stratification for eye colour. This result is not surprising as different variants seems to be involved in MM and eye colour (ie combination of SNP 3 and 7 for melanoma and SNP 5 for eye colour). Furthermore, OCA2 genotypes significantly increase the fit of a logistic regression on $\mathrm{MM}$ after taking into account all pigmentation characteristics and an important susceptibility melanoma gene, $M C 1 R$, enhancing this result.

The physiopathological basis of the role of OCA2 in human pigmentation and melanoma susceptibility can be extrapolated from animal models. ${ }^{17}$ The eumelanin content, the proliferation, and the differentiation of melanoblasts and melanocytes are all greatly reduced $p$ mutant mice. ${ }^{17}$ It therefore seems quite reasonable to assume that the quantity and/or quality of melanin, that determines part of the risk of skin cancer, is strongly influenced by the OCA 2 protein. In fact, a decrease of eumelanin in OCA2-variant melanocytes could contribute to mutagenesis and confer susceptibility to $\mathrm{MM}$ and nonmelanoma skin cancer by enhancing toxicity of free radicals following ultraviolet exposure.

In addition, OCA2 could also increase melanoma susceptibility via mechanisms that are in part independent of the melanogenesis process. This is supported by the fact that the pink-eyed dilution protein increases cellular sensitivity to arsenicals and other metalloids by modulating the intracellular glutathione metabolism that is involved in the detoxification of reactive free radicals of oxygen. ${ }^{11}$ Loss-of-function OCA2 mutant melanocytes 
could become more resistant to photo-induced stress and perhaps go on to be transformed more easily into MM cells.

In summary, our findings show that the OCA2 genotype influences melanoma risk, even after pigmentation characteristics are taken into account, and that the risk is likely the result of several OCA2 variants, possibly interacting.

\section{Acknowledgements}

A-S Jannot gratefully acknowledges the support of the Fondation pour la Recherche Médicale (FRM). This work was supported by grants from L'Assistance Publique des Hôpitaux de Paris (AP-HP) and from La Société Française de Dermatologie (SFD).

\section{References}

1 Dreno B, Wallon-Dumont G: Epidemiology of melanoma. Presse Med 2003; 32: 30-32.

2 Kamb A, Shattuck-Eidens D, Eeles R et al: Analysis of the p16 gene (CDKN2) as a candidate for the chromosome 9p melanoma susceptibility locus. Nat Genet 1994; 8: 23-26.

3 Hussussian CJ, Struewing JP, Goldstein AM et al: Germline p16 mutations in familial melanoma. Nat Genet 1994; 8: 15-21.

4 Zuo L, Weger J, Yang Q et al: Germline mutations in the p16INK4a binding domain of CDK4 in familial melanoma. Nat Genet 1996; 12: $97-99$.

5 Holland EA, Schmid H, Kefford RF, Mann GJ: CDKN2A (P16(INK4a)) and CDK4 mutation analysis in 131 Australian melanoma probands: effect of family history and multiple primary melanomas. Genes Chromosomes Cancer 1999; 25: 339-348.

6 Palmer JS, Duffy DL, Box NF et al: Melanocortin-1 receptor polymorphisms and risk of melanoma: is the association explained solely by pigmentation phenotype? Am J Hum Genet 2000; 66: 176-186.

7 Kennedy C, ter Huurne J, Berkhout $\mathrm{M}$ et al: Melanocortin 1 receptor (MC1R) gene variants are associated with an increased risk for cutaneous melanoma which is largely independent of skin type and hair color. J Invest Dermatol 2001; 117: 294-300.

8 Matichard E, Verpillat P, Meziani R et al: Melanocortin 1 receptor (MC1R) gene variants may increase the risk of melanoma in France independently of clinical risk factors and UV exposure. J Med Genet 2004; 41: e13.

9 Lee ST, Nicholls RD, Bundey S, Laxova R, Musarella M, Spritz RA: Mutations of the $\mathrm{P}$ gene in oculocutaneous albinism, ocular albinism, and Prader-Willi syndrome plus albinism. N Engl J Med 1994; 330: 529-534.

10 Ramsay M, Colman MA, Stevens G et al: The tyrosinase-positive oculocutaneous albinism locus maps to chromosome 15q11q12. Am J Hum Genet 1992; 51: 879-884

11 Staleva L, Manga P, Orlow SJ: Pink-eyed dilution protein modulates arsenic sensitivity and intracellular glutathione metabolism. Mol Biol Cell 2002; 13: 4206-4220.

12 Gardner JM, Nakatsu Y, Gondo Y et al: The mouse pink-eyed dilution gene: association with human Prader-Willi and Angelman syndromes. Science 1992; 257: 1121-1124.

13 Bianchi AB, Fischer SM, Robles AI, Rinchik EM, Conti CJ: Overexpression of cyclin D1 in mouse skin carcinogenesis. Oncogene 1993; 8: 1127-1133.

14 Rinchik EM, Bultman SJ, Horsthemke B et al: A gene for the mouse pink-eyed dilution locus and for human type II oculocutaneous albinism. Nature 1993; 361: 72-76.

15 Rosemblat S, Sviderskaya EV, Easty DJ et al: Melanosomal defects in melanocytes from mice lacking expression of the pink-eyed dilution gene: correction by culture in the presence of excess tyrosine. Exp Cell Res 1998; 239: 344-352.
16 Orlow SJ, Brilliant MH: The pink-eyed dilution locus controls the biogenesis of melanosomes and levels of melanosomal proteins in the eye. Exp Eye Res 1999; 68: 147-154.

17 Hirobe T, Kawa Y, Mizoguchi M, Ito S, Wakamatsu K: Effects of genic substitution at the pink-eyed dilution locus on the proliferation and differentiation of mouse epidermal melanocytes in vivo and in vitro. J Exp Zool 2002; 292: 351-366.

18 Ozeki H, Ito S, Wakamatsu K, Hirobe T: Chemical characterization of hair melanins in various coat-color mutants of mice. J Invest Dermatol 1995; 105: 361-366.

19 Tamate HB, Hirobe T, Wakamatsu K, Ito S, Shibahara S, Ishikawa $\mathrm{K}$ : Levels of tyrosinase and its mRNA in coat-color mutants of C57BL/10J congenic mice: effects of genic substitution at the agouti, brown, albino, dilute, and pink-eyed dilution loci. J Exp Zool 1989; 250: 304-311.

20 Lamoreux ML, Zhou BK, Rosemblat S, Orlow SJ: The pinkeyeddilution protein and the eumelanin/pheomelanin switch: in support of a unifying hypothesis. Pigment Cell Res 1995; 8: 263-270.

21 Chen K, Manga P, Orlow SJ: Pink-eyed dilution protein controls the processing of tyrosinase. Mol Biol Cell 2002; 13: 1953-1964.

22 Toyofuku K, Valencia JC, Kushimoto T et al: The etiology of oculocutaneous albinism (OCA) type II: the pink protein modulates the processing and transport of tyrosinase. Pigment Cell Res 2002; 15: 217-224.

23 Lee ST, Nicholls RD, Jong MT, Fukai K, Spritz RA: Organization and sequence of the human P gene and identification of a new family of transport proteins. Genomics 1995; 26: 354-363.

24 Ancans J, Flanagan N, Hoogduijn MJ, Thody AJ: P-locus is a target for the melanogenic effects of MC-1R signaling: a possible control point for facultative pigmentation. Ann NY Acad Sci 2003; 994: 373-377.

25 Sturm RA, Duffy DL, Box NF et al: The role of melanocortin-1 receptor polymorphism in skin cancer risk phenotypes. Pigment Cell Res 2003; 16: 266-272.

26 Rebbeck TR, Kanetsky PA, Walker AH et al: P gene as an inherited biomarker of human eye color. Cancer Epidemiol Biomarkers Prev 2002; 11: 782-784.

27 Newton JA, Bataille V, Griffiths $\mathrm{K}$ et al: How common is the atypical mole syndrome phenotype in apparently sporadic melanoma? I Am Acad Dermatol 1993; 29: 989-996.

28 Miller SA, Dykes DD, Polesky HF: A simple salting out procedure for extracting DNA from human nucleated cells. Nucleic Acids Res 1988; 16: 1215

29 Matichard E VP, Meziani R, Gérard B et al: Melanocortin 1 receptor (MC1R) gene variants increase the risk of melanoma in France independently of clinical risk factors and UV exposure. J Med Genet 2004; 41: e13.

30 Frandberg PA, Doufexis M, Kapas S, Chhajlani V: Human pigmentation phenotype: a point mutation generates nonfunctional MSH receptor. Biochem Biophys Res Commun 1998; 245: 490-492.

31 Schioth HB, Phillips SR, Rudzish R, Birch-Machin MA, Wikberg JE, Rees JL: Loss of function mutations of the human melanocortin 1 receptor are common and are associated with red hair. Biochem Biophys Res Commun 1999; 260: 488-491.

32 Jimenez-Cervantes C, Germer S, Gonzalez P, Sanchez J, Sanchez CO, Garcia-Borron JC: Thr40 and Met122 are new partial loss-offunction natural mutations of the human melanocortin 1 receptor. FEBS Lett 2001; 508: 44-48.

$33 \mathrm{Xu}$ X, Thornwall M, Lundin LG, Chhajlani V: Val92Met variant of the melanocyte stimulating hormone receptor gene (letter; comment). Nat Genet 1996; 14: 384.

34 Mas JS, Sanchez CO, Ghanem G et al: Loss-of-function variants of the human melanocortin-1 receptor gene in melanoma cells define structural determinants of receptor function. Eur J Biochem 2002; 269: 6133-6141.

35 Valverde P, Healy E, Sikkink S et al: The Asp84Glu variant of the melanocortin 1 receptor (MC1R) is associated with melanoma. Hum Mol Genet 1996; 5: 1663-1666. 
36 Devlin B, Risch N: A comparison of linkage disequilibrium measures for fine-scale mapping. Genomics 1995; 29: 311-322.

37 Jannot AS, Essioux L, Reese MG, Clerget-Darpoux F: Improved use of SNP information to detect the role of genes. Genet Epidemiol 2003; 25: $158-167$.

38 Oetting WS, King RA: Molecular basis of albinism: mutations and polymorphisms of pigmentation genes associated with albinism. Hum Mutat 1999; 13: 99-115.

39 Sturm RA, Teasdale RD, Box NF: Human pigmentation genes: identification, structure and consequences of polymorphic variation. Gene 2001; 277: 49-62.
40 Drysdale CM, McGraw DW, Stack CB et al: Complex promoter and coding region beta 2 -adrenergic receptor haplotypes alter receptor expression and predict in vivo responsiveness. Proc Natl Acad Sci USA 2000; 97: 10483-10488.

41 Duffy DL, Box NF, Chen W et al: Interactive effects of MC1R and OCA2 on melanoma risk phenotypes. Hum Mol Genet 2004; 13: $447-461$.

42 Sturm RA, Duffy DL, Box NF et al: Genetic association and cellular function of MC1R variant alleles in human pigmentation. Ann NY Acad Sci 2003; 994: 348-358.

43 Frudakis T, Thomas M, Gaskin Z et al: Sequences associated with human iris pigmentation. Genetics 2003; 165: 2071-2083. 